\title{
The Sharing Economy and Marketing: A Review and Future Research (An Abstract)
}

\author{
Syed Tariq Anwar
}

\begin{abstract}
The sharing economy continues to grow in the USA, developed countries, and emerging markets. The sharing economy connects sellers and buyers through unique digital platforms and P2P business models. The sharing economy can be a part of "futuristic marketing" related to the Internet and web-based interactions. It is definitely an extension of new marketing practices that encompass consumers, business, society, virtual networks, etc. The sharing economy can be defined as sharing of consumer and industrial products, services, and resources which are used by consumers and businesses. The sharing economy is inherently synonymous with collaborative consumption areas that help consumers and firms to lower cost, seek economies of scale, and remain competitive in the fast-changing business and digital world.

The literature on the sharing economy continues to grow because of its heightened interest and popularity. Since the topic is new, the sharing economy and its related areas have not been examined thoroughly in marketing. There are a few studies available on the sharing economy which discussed marketing and its practices. Areas such as collaborative consumption, digital markets, and emerging industries are important topics in the sharing economy. Because of the significance and application of the sharing economy, this paper aims at analyzing and discussing the sharing process and its multidisciplinary literature and research domains. The paper reviews over 80 multidisciplinary studies which have been published on the topic and its related areas. The work's main contribution is to systematically review the literature and its multifaceted discourses and applications. We believe that future research in marketing can benefit by looking at the sharing economy and its multidisciplinary reviews.
\end{abstract}

References available on request.

S.T. Anwar $(\bowtie)$

West Texas A\&M University, Canyon, TX, USA

e-mail: sanwar@mail.wtamu.edu 